EGU21-10322

https://doi.org/10.5194/egusphere-egu21-10322

EGU General Assembly 2021

(c) Author(s) 2021. This work is distributed under

the Creative Commons Attribution 4.0 License.

\title{
Integrated water vapour content retrievals from ship-borne GNSS receivers during EUREC4A
}

\author{
Pierre Bosser ${ }^{1}$, Olivier Bock ${ }^{2,3}$, Cyril Flamant ${ }^{4}$, Sandrine Bony ${ }^{5}$, and Sabrian Speich ${ }^{6}$ \\ ${ }^{1}$ ENSTA Bretagne, Lab-STICC, Brest, France (pierre.bosser@ensta-bretagne.fr) \\ ${ }^{2}$ Université de Paris, Institut de physique du globe de Paris, CNRS, IGN, Paris, France (olivier.bock@ipgp.fr) \\ ${ }^{3}$ ENSG-Géomatique, IGN, Marne-la-Vallée, France (olivier.bock@ipgp.fr) \\ ${ }^{4}$ LATMOS/IPSL, UMR 8190 CNRS, SU-UVSQ, Paris, France (cyrille.flamant@latmos.ipsl.fr) \\ ${ }^{5}$ LMD/IPSL, UMR 8539 CNRS, Sorbonne Université, UPMC, Paris, France (bony@Imd.jussieu.fr) \\ ${ }^{6}$ LMD/IPSL, UMR 8539 CNRS, ENS-Ecole Polytechnique-SU, Paris, France (sabrina.speich@Imd.ens.fr )
}

In the framework of the EUREC4A campaign, integrated water vapour (IWV) contents were retrieved over the open Tropical Atlantic Ocean using Global Navigation Satellite System (GNSS) data acquired from three research vessels : R/V Atalante, R/V Maria S. Merian, and R/V Meteor. This study describes the GNSS processing method and compares the GNSS IWV retrievals with IWV estimates from the ECMWF fifth ReAnalysis (ERA5), from the MODIS infra-red products, and from terrestrial GNSS stations located along the tracks of the ships. The ship-borne GNSS IWVs retrievals from R/V Atalante and R/V Meteor compare well with ERA5, with small biases $(-1.62$ $\mathrm{kg} / \mathrm{m} 2$ for R/V Atalante and $+0.65 \mathrm{~kg} / \mathrm{m} 2$ for R/V Meteor) and a RMS difference about $\sim 2.3 \mathrm{~kg} / \mathrm{m} 2$. The results for the R/V Maria S. Merian are found to be of poorer quality, with RMS difference of about $6 \mathrm{~kg} / \mathrm{m} 2$ which are very likely due to the location of the GNSS antenna on this R/V prone to multipath effects. The comparisons with ground-based GNSS data confirm these results. The comparisons of all three R/V IWV retrievals with MODIS infra-red product show large RMS differences of $5-7 \mathrm{~kg} / \mathrm{m} 2$, reflecting the enhanced uncertainties of this satellite product in the tropics. These ship-borne IWV retrievals are intended to be used for the description and understanding of meteorological phenomena that occurred during the campaign, east of Barbados, Guyana and northern Brazil. 